\title{
THE RIGHT TO PRIVACY AND DRUG-TESTING IN SPORT IN SOUTH AFRICA: COULD THE NEW ZEALAND CASE OF CROPP V JUDICIAL COMMITTEE PROVIDE SOME GUIDANCE?
}

Jean Wilké*

$B A L L B$ LLM

Teaching and Research Assistant in the Law Faculty University of Cape Town

\section{SUMMARY}

This article examines the right to privacy of athletes who are required to submit to drug tests. In South Africa, the right to privacy of an athlete with regard to drugtesting has not been challenged in the courts. However, the courts in New Zealand have had an opportunity to examine the right to privacy of an athlete in terms of drugtesting in sport. Therefore, the article discusses whether the decision in the New Zealand case of Cropp $v$ Judicial Committee may provide some guidance to South African courts in the adjudication of whether the infringement and the limitation on the right to privacy in the context of drug-testing in sport can be reasonable and justified and concludes that such infringement may be reasonable and justified if a court is to consider a limitation of the right to privacy in terms of section 36 of the Constitution of the Republic of South Africa, 1996 as well as consent and safety.

INTRODUCTION

"Athletes ... do not abandon their human rights once they enter the boundary lines onto the field of play."

"Athletes possess a right to have the privacy of their bodies and belongings or effects respected."

As the professionalism of sport continues to increase, athletes continue to look for ways to be the best, the strongest, and the fastest. And as athletes seek to achieve these goals, they look for ways which will help them do so. Athletes have begun to turn to medicine and science in order to assist them

* This article is based on a paper that was presented at the Sports Law Colloquium 2012 held in Bloemfontein by the South African Institute for Drug-Free Sport and The Institute of Development and Labour Law (UCT).

Singh "Human Rights and Sport" 2006 http://www.docstoc.com/docs/19767069/SPORTAND-HUMAN-RIGHTS\# (accessed 2012-09-10).

2 Ibid. 
in achieving and enhancing their performance. ${ }^{3}$ This has resulted in the need to control and monitor the use of drugs by athletes. Such control and monitoring is administered in terms of the World Anti-Doping Agency (WADA) Code ${ }^{4}$ which provides for a prohibited list of banned substances as well as providing for the use of drug tests to test for the banned substances. ${ }^{5}$

Drug-testing in sport is also prescribed by law by means of the creation of the WADA and various pieces of legislation in a particular country. WADA cannot force a country to take a particular stance on a certain issue as governments "cannot be legally bound by a non-governmental document such as the World Anti-Doping Code". ${ }^{6}$ However, WADA can, with the help if an international convention, highlight the responsibilities of governments and can, through the use of the convention, state that a country cannot compete in a particular sport unless they sign up to the WADA Code. ${ }^{7}$ After this is done, the country will then create domestic legislation and rules which follow the convention. Sporting bodies will also create their own rules and regulations dealing with drug-testing.

In South Africa, as part of the WADA Code and the policies of the South African Institute for Drug Free Sport (SAIDS) and the particular sports bodies, South African athletes are required to submit to drug tests. The mission of the SAIDS is to "detect, deter and prevent the use of prohibited substances and methods in the South African and the international sporting environment, which are contrary to the principles of fair play and the health and well being of athletes." 8 Section 11 of the South African Institute for Drug-Free Sport Act ${ }^{9}$ (SAIDS Act) provides for the powers and duties of the SAIDS. In terms of this provision, the SAIDS shall, among other duties, adopt and implement the anti-doping rules and policies which form part of the WADA Code and collect samples from athletes for the purposes of drugtesting at a WADA accredited laboratory.

Although athletes are required to accept the anti-doping rules ${ }^{11}$ and undergo drug-testing, as a condition of participation in a particular sport,

3 Jakoet, Lubbe and Basson "Sport and Drugs" in Basson and Loubser (eds) Sport and the Law in South Africa Issue 9 (2011) 10-1.

4 "World Anti-Doping Code" (2009) http://www.wada-ama.org/Documents/World_Anti-Doping _Program/WADP-The-Code/WADA_Anti-Doping_CODE_2009_EN.pdf (accessed 2012-0910).

5 Ibid. See Article 4 and Article 5. The WADA Doping Control process can be found at http://www.drugfreesport.org.za/wp-content/themes/dfs/pdf/WADA_Doping-Control-process .pdf (accessed 2012-12-03).

6 See http://www.wada-ama.org/en/World-Anti-Doping-Program/Governments/ (accessed on 2012-11-26).

7 Countries are required to sign the United Nation's Educational, Scientific and Cultural Organisation's International Convention Against Doping in Sport (adopted 19 October 2005, entered into force 1 February 2007) and the Copenhagen Declaration on Anti-Doping in Sport (March 2003). After signing these, countries create their own domestic legislation dealing with anti-doping in sport.

8 Jakoet et al in Basson and Loubser (eds) Sport and the Law in South Africa 10-3.

914 of 1997.

$10 \mathrm{~S} 11(2)(\mathrm{f})$.

11 Jakoet et al in Basson and Loubser (eds) Sport and the Law in South Africa 10-24. The Anti-Doping Rules "are sports rules governing the conditions under which sport is played. 
athletes "do not abandon their human rights once they enter the boundary lines onto the field of play". ${ }^{12}$ As a result, the requirement of undergoing a drug test has led to questions over whether such a requirement is contrary to the right to privacy or whether such testing is reasonable and justified.

This issue of privacy and drug-testing in sport comes in many forms and can be found in many countries. Questions of privacy can arise in the following instances, when an athlete is required to take the drug test, the "whereabouts" rule, ${ }^{13}$ and when there is a question over making the results of the test public knowledge. ${ }^{14}$ This paper will focus on the first of the issues regarding privacy.

In South Africa, the right to privacy is governed under the common law and is also specifically entrenched as a fundamental right in section 14 of the Constitution of the Republic of South Africa, 1996. In the context of sport in South Africa, the courts have not yet adjudicated a case in which the right to privacy in drug-testing in sport has been examined. However, in New Zealand, the courts have, in recent years, had the opportunity to examine the right to privacy in the context of drug-testing in sport. Therefore, this paper seeks to examine whether the decision in the New Zealand case of Cropp v Judicial Committee ${ }^{15}$ may provide some guidance to South African Courts in the adjudication of whether the infringement and the limitation on the right to privacy in the context of drug-testing in sport can be reasonable and justified.

\section{CROPP $V$ JUDICIAL COMMITTEE: THE JUDGMENTS OF THE VARIOUS COURTS}

The New Zealand case of Lisa Cropp is a recent example of a case which dealt specifically with the issue of the right to privacy of an athlete who had to submit to a drug test and the question of whether her right to privacy could be justifiably limited by taking into account section 5 of the New Zealand Bill of Rights Act 1990 (BORA), as well as issues of consent and safety. In the various judgments of the different courts, the courts examined, amongst

Athletes, Athlete Support Personnel, and other Persons accept these rules as a condition of participation and shall be bound by them".

12 Singh 2006 http://www.docstoc.com/docs/19767069/SPORT-AND-HUMAN-RIGHTS\# (accessed 2012-09-10).

13 For a discussion on the "whereabouts" rule, see Halt "Where is the Privacy in WADA's "Whereabouts" Rule?" 200920 Marq Sports LR 267. The "whereabouts" rule is used for outof-competition testing of an elite pool of athletes who must provide their whereabouts information (eg, that they will be at home at a certain time every day or that they will be on holiday at a certain place for a certain period) in order for testers to conduct unannounced testing. Article 14.3 of the WADA Code supra sets out the "whereabouts" rule.

14 See, eg, Athletics New Zealand v Liza Hunter-Galvan ST 07/09 [23]-[26], where this was raised. This also arises in medical testing in sport as was the case where the results of the gender test conducted on Caster Semenya were made public knowledge thereby violating her right to privacy (Gevisser "South African Angst" 3 September 2009 The New York Times www.nytimes.com/2009/09/03/opinion/03iht-edgevisser.html? $r=3 \& s c p=1 \& s q=g e v i s s e r \& s t=$ cse (accessed 2012-09-10).

15 Cropp v A Judicial Committee [2007] NZAR 465 (HC) (High Court); Cropp v Judicial Committee [2008] NZAR 50 (CA) (Court of Appeal); and Lisa Cropp v Judicial Committee [2008] 3 NZLR 774 (SCNZ) (Supreme Court). 
other issues, whether Cropp's right to privacy, as found in section 21 of the BORA, had been infringed and had therefore led to an invalidity of her test or whether such infringement could be justified by taking certain factors into account.

Cropp was a jockey who, after a race in 2005 , was asked to provide a urine sample for drug-testing. The urine sample tested positive for amphetamine and methamphetamine. As a result, Cropp was found to be have breached Rule 528 of the Constitution and New Zealand Rules of Racing (the Rules). ${ }^{16}$ This case was first heard by a Judicial Committee. Although the proceedings before the Judicial Committee were not finalized when Cropp approached the High Court, the Judicial Committee made a finding in 2007 regarding jurisdictional and technical issues and the application of the BORA. ${ }^{17}$ The Judicial Committee stated that they did not agree with Cropp that the BORA and, in particular, section 21 applied to her case. ${ }^{18}$ Pursuant to this, Cropp instituted proceedings in the High Court seeking a declaration that the Rules are unlawful and invalid "as they purport to provide authority for the obtaining of bodily samples; and that the sample taken from Ms Cropp and produced in evidence against her was therefore unlawfully obtained".

In the proceedings in the High Court, Cropp challenged the Rules of the New Zealand Thoroughbred Racing Inc. (NZTR). It was argued that the requirement for a jockey to provide a urine sample for a drug test breached her rights as this requirement is in violation of the BORA and is not authorized by the Racing Act $2003 .{ }^{20}$

The High Court agreed that the BORA applied to the case of Cropp. The Court, in examining the Racing Act, looked at section 29 of the Act and found that Parliament could not be said to have intentionally made legislation which would be contrary to fundamental human rights or give NZTR the power to make rules that would be in conflict with certain human rights. ${ }^{21}$ Andrews $\mathrm{J}$ considered whether there had been a breach of a human right and whether such breach could be said to be reasonable in terms of section 5 of the BORA. ${ }^{22}$

Andrews $\mathrm{J}$ found that the taking of urine samples for drug-testing was an invasion of a person's privacy as is guaranteed by section 21 of the BORA and was therefore a breach of the right. ${ }^{23}$ However, Andrews $\mathrm{J}$ also examined the reasonableness of the limit placed on Cropp's right to privacy and found that the reason for the drug-testing was for race-day safety. ${ }^{24}$ Although the Judge accepted that the purpose of the drug test was not

Cropp v A Judicial Committee (High Court) supra [4]-[6].

Cropp v A Judicial Committee (High Court) supra [7] and [8].

Lisa Cropp v Judicial Committee (Supreme Court) supra [5].

Lisa Cropp v Judicial Committee (Supreme Court) supra [8].

Cropp v A Judicial Committee (High Court) supra [27]. S 29(2)(d) of the Racing Act deals with the power to make rules for "the conduct and control of race meetings, including safety requirements".

21 Cropp v A Judicial Committee (High Court) supra [43].

22 Cropp v A Judicial Committee (High Court) supra [48].

23 Cropp v A Judicial Committee (High Court) supra [53].

24 Cropp v A Judicial Committee (High Court) supra [79]-[80]. 
negated by the fact that the jockey was still able to ride in the race after supplying a sample, Andrews J was satisfied that "the purpose of the drugtesting rules is to ensure safety through identifying those taking drugs and deterring those who may do so." ${ }^{25}$ Andrews $\mathrm{J}$ found that the limitation on the right was not disproportionate to the importance of the Rule's objective of race-day safety and so there was no breach of Cropp's right to privacy. ${ }^{26}$

The Court of Appeal agreed with the judgment of the High Court, but they agreed on a different basis. ${ }^{27}$ The Court of Appeal focussed on the issues of harm and consent rather than on a section 21 breach. The Court of Appeal found that a breach of section 21 of the BORA depended on whether there had been the absence of consent on the part of Cropp. ${ }^{28}$ Fogarty $\mathrm{J}$ found that the consent by the individual comes from submitting to the rules of the sporting organization. ${ }^{29}$ The Court of Appeal therefore found that there was no breach of Cropp's privacy. The court stated that "Counsel for Ms Cropp had had to acknowledge that random testing for use of drugs was a method used all around the world in similar situations as a means of preventing harm." ${ }^{30}$ The court found that Cropp's privacy had not been violated as she had consented to the drug-testing by submitting to the rules of the NZTR. ${ }^{31}$ The appeal was accordingly dismissed.

Cropp approached the Supreme Court to appeal the decision. The court had to consider whether the taking of the urine sample was an unreasonable search that would infringe on her right under section 21 of the BORA which would, as result, cause the Rule requiring her to supply a urine sample to be invalid. ${ }^{32}$ In dealing with the issue of consent, the court found that "any power to make a rule conferring the entitlement to conduct a search does not authorize searches that would be unreasonable and so infringe protected rights under s[ection] 21."33 The court stated that Cropp could not have been said to consent to be drug-tested if the rule requiring her to supply a urine sample was invalid. ${ }^{34}$ The court further stated that the consent could also not be used to put the particular search outside the protection of section 21 of the BORA. ${ }^{35}$

The court held that Cropp's consent was of no significance in examining whether the giving of the urine sample complied with section $21 .^{36}$ The court chose to focus instead on the wording of the legislation which provided for the drug-testing. The court found that the purpose of the rule was to allow for safety at race meetings and so the Rule was reasonable. ${ }^{37}$ The court agreed

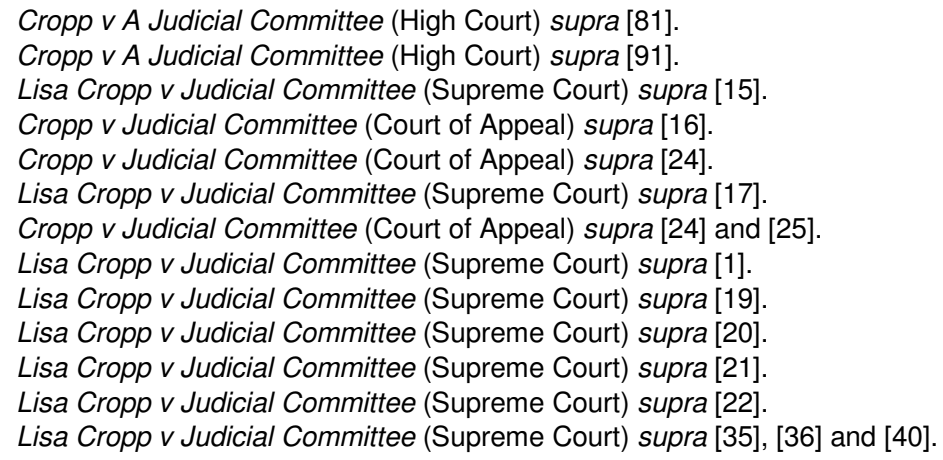


that the requirement to supply a urine sample did involve an intrusion of personal privacy, but the court looked at the risk factor should the jockeys not be tested and found that the racing code did have the power to impose a random drug-testing regime. ${ }^{38}$ The Supreme Court therefore dismissed the appeal.

It is clear from the judgments of the various courts that Cropp's right to privacy may have been infringed, but such infringement and a limitation of her right to privacy could be justified, not necessarily by only looking at the BORA, but also if one looked at issues such as safety and consent.

Therefore, it is clear that in discussing whether an infringement of an athlete's privacy was reasonable with regard to the taking of a urine sample for drug-testing, it is necessary to examine the BORA and, in particular, sections 5 and 21 of that Act in determining whether the BORA can apply and whether the courts were correct in finding that the limitation of the right to privacy could be justified.

\section{SECTION 21 AND SECTION 5 OF THE BORA}

Section 21 of the BORA states:

"Everyone has the right to be secure against unreasonable search or seizure, whether of the person, property, or correspondence or otherwise."

\section{Section 5 of the BORA provides:}

"Subject to section 4, the rights and freedoms contained in this Bill of Rights may be subject only to such reasonable limits prescribed by law as can be demonstrably justified in a free and democratic society."

Rights in the BORA can have a horizontal or vertical application. In the case of drug-testing in sport, we can say that a horizontal relationship exists between the national anti-doping agency, Drug Free Sport New Zealand, and the athlete, especially if we take into account the existence of any legislation which directly governs sport or creates rules for the particular sport, such as the Sports Anti-Doping Act 2006 and the Racing Act. As a result of this, the BORA will need to be examined in dealing with the athlete's right to privacy when looking at the requirement for a drug test either because there is consent or because it is necessary for the safety of the sport. Section 21 protects against a search and seizure which is unreasonable. This section protects the right to privacy of an individual as it protects against the unreasonable search of a person, that person's property, or correspondence. The Commentary ${ }^{39}$ on the BORA points to the fact that the Court of Appeal had referred 'to the 'touchstone' in $\mathrm{s} 21$ of BORA as being 'the protection of reasonable expectations of privacy.", 40 The Commentary also states that section 21 of BORA is there to ensure that no person is subjected to "constraints and ill-effects" which can be associated with an unreasonable search and seizure other than when a search and

38 Lisa Cropp v Judicial Committee (Supreme Court) supra [32].

39 Butler and Butler The New Zealand Bill of Rights Act: A Commentary (2005).

40 Butler and Butler The New Zealand Bill of Rights Act: A Commentary 542. 
seizure has been authorized by the law. ${ }^{41}$ Therefore, a question which arises from section 21 is: what is an unreasonable search and seizure and what is a reasonable search and seizure which would limit the person's right?

In imposing a limit on a right such as that found in section 21 , it is necessary to focus on the wording of section 5 and, in particular, the words "reasonable", "prescribed by law" and "demonstrably justified in a free and democratic society". Therefore an infringement needs to meet these requirements and must be reasonable in order for it to be justified. ${ }^{42}$

For an infringement of the right to be reasonable and therefore justified, such infringement needs to pass a section 5 enquiry which aims to determine "the significance of the values underlying the BORA in the particular case or context; the importance in the public interest of the intrusion on the particular BORA right; the effectiveness of the intrusion in protecting the interests put forward to justify those limits sought to be placed on the BORA right in the particular case; and the proportionality of the intrusion". ${ }^{43}$ This enquiry looks at the reasonableness of the limitation in order to determine if such a limitation is "demonstrably justified in a free and democratic society".

If we are to apply section 21 and section 5 to the case of an athlete who is required to take a drug test, we would be able to determine if their privacy has been infringed and if so whether such an infringement is reasonable and justified.

The taking of a urine or blood sample can be viewed as a search and seizure of that person. The provision of a urine or blood sample leads to the question of whether such an action infringes on that athlete's right to privacy and whether such infringement is justified. Therefore, it would be necessary to conduct a section-5 enquiry in order to determine if the limitation is "reasonable", "prescribed by law" and "demonstrably justified in a free and democratic society".

With regard to the first part of the enquiry, in order for a limitation on the right to be justified, it is necessary to look at the significance of the values underlying the BORA in the case of an athlete being required to submit to a drug test. Section 21 seeks to protect a person from an illegal or unreasonable search and seizure. However, in some cases a search and seizure, whilst infringing on that person's right to privacy, may be justified.

The second part of the enquiry looks at the importance in the public interest of the intrusion on the right. Is it in the interest of the public that an athlete be tested for drugs? It would seem that it is in the public interest that athletes be tested for illegal drugs in order to deter athletes from taking drugs and to ensure that all athletes (the athlete and the competitors) are safe when taking part in the sport and to protect the integrity of the sport and the sport's organization.

Ibid.

Joseph Constitutional and Administrative Law in New Zealand 3ed (2007) 1162.

43 Butler and Butler The New Zealand Bill of Rights Act: A Commentary 589; and Ministry of Transport v Noort [1992] 3 NZLR 260 (CA) 283-284. 
The third part of the enquiry is concerned with the effectiveness of the intrusion in protecting the interests put forward to justify the limits sought. The intrusion of the athlete's privacy is effective because by requiring a blood or urine sample to be taken, that sport's organization will find those athletes who are taking drugs and deters others, through the use of sanctions imposed ${ }^{44}$ thereby protecting the interests of the sport as well as the interests of the athletes involved. This also helps in protecting the interests of the athlete concerned and it seeks to protect them and ensure their safety.

The final part of the section 5 enquiry examines the proportionality of the intrusion. Proportionality refers to the balancing of different interests and the weighing up of competing values. ${ }^{45}$

In weighing up different interests, it would seem that public interest could supersede the athlete's right to privacy. With this, one would need to weigh up the privacy of the athlete against the protection of society and the other athletes. Public safety is therefore brought into the argument of whether an athlete's right to privacy should be limited. Angela Schneider states that one argument used to justify a ban on doping is harm. ${ }^{46}$ She identifies four types of harm, namely, harm to users, harm to other athletes, harm to society, and harm to the sport community. ${ }^{47}$ This argument of harm could be used to justify the limiting of an athlete's right to privacy by requiring them to provide a urine sample.

By requiring an athlete to provide a urine sample, it could be argued that the interests and protection as a whole are being upheld. With regard to the harm to the user, the providing of the urine sample could protect the athlete. First, the drug test could be a deterrent through the use of sanctions imposed if the sample is positive. Secondly, should the sample be positive, the athlete will be prevented from competing thereby minimizing any injury that may happen to them as a consequence of taking the drugs. By requiring a drug test, harm to other athletes is also minimized, as that athlete, who tests positive for a prohibited substance (especially in such sports where that athlete's drug-taking could directly harm others), would not be able to compete in further competitions.

Doping also causes harm to society and the sports community. If a national sporting hero tested positive for drugs, such stigma causes a great deal of problems for the sport. A positive test by an athlete can cause the public to lose faith in that sport and athlete and it causes the sporting community to be viewed in a negative light.

It is therefore necessary to look at the infringement of the right to privacy of the athlete in providing a sample on one hand and, on the other hand, the rights and interests of the other athletes to be safe and for the sport to

44 See Articles 10-12 of the WADA Code supra. See also, Dunn, Thomas, Swift, Burns and Mattick "Drug Testing in Sport: The Attitudes and Experiences of Elite Athletes" 201021 International Journal of Drug Policy 330331.

45 S v Makwanyane 1995 (3) SA 391 (CC) [104]

46 Schneider "Privacy, Confidentiality and Human Rights in Sport" Autumn 2004 7(3) Sport in Society 438446.

47 Ibid. 
uphold its integrity. An athlete's right to privacy is not completely limited. It is only limited in so far as the athlete will be required to provide a urine sample to be tested for drugs.

An athlete, in becoming part of that sport's organization, consents to the rules and regulations of the sport's organization and is aware of the possibility that he/she will be tested. They are aware of the fact that they may be required to provide a urine or blood sample at some stage during their sporting career and are therefore aware of the fact that there will be consequences should that sample test positive. It would also seem that an athlete is unlikely to challenge the infringement of his/her privacy should his/her sample test negative for drugs.

In New Zealand, by using a section 5 enquiry, it is clear to see that the infringement of athletes' right to privacy by requiring them to take a drug test can be said to be reasonable and justified. It is in the interest of the athletes, other athletes and the public that drug tests are conducted in order to ensure that the sport remains fair and safe. Requiring an athlete to provide a urine sample when he/she knows he/she are required to do so cannot be said to be a disproportionate intrusion if one takes into account the reason behind the test and the fact that should that test be negative, the athletes may not say that their right to privacy has been infringed. Consequently, a limit on the right to privacy is reasonable, prescribed by law and is justified.

\section{WERE THE COURTS IN THE CROPP CASE CORRECT?}

It is clear that requiring Lisa Cropp to provide a urine sample can be said to infringe on her right to privacy found in section 21 as it is a search and seizure of her person. However, such infringement could be justified and the limitation on her right could be reasonable given the circumstances. Cropp knew that, as a professional jockey, she would be required to give a urine sample for drug-testing. Although the Court of Appeal commented that her consent was not made voluntarily, Cropp had submitted to the Rules of the NZTR and the Racing Act and had thereby consented to being tested if she wished to remain a professional jockey. As Angela Schneider has said regarding consent:

"Consent can be expressed or implied. For example, when an individual agrees to become a member of a sport governing body they agree to play the sport according to its rules. If the individual is not willing to follow the rules he or she does not have to participate in the sport. If the sport's rules include rules against doping, the individual is said to consent to those rules (even if he or she has not taken the time or trouble to read and understand them completely)."

Cropp submitted, in the High Court, that she was still allowed to ride in the other races after having given a urine sample and so the test could not be for the purpose of safety. ${ }^{49}$ However, this is not the case. It is in the public interest that the athletes are tested for drugs and do not take drugs as they

48 Schneider 2004 Sport in Society 443.

49 Cropp v A Judicial Committee (High Court) supra [71]. 
could affect the safety of the other jockeys during a race and could also affect the safety of Cropp. By taking drugs, Cropp was not only causing harm to herself, but she was also harming other jockeys, society and the NZTR. She could be said to be causing harm to herself by taking drugs as the drugs could result in her injuring herself during a race. Cropp also argued in the High Court that her taking the drugs did not affect the other jockeys and would not harm them. ${ }^{50}$ However, by being under the influence of the drugs while racing, she could also cause harm to the other jockeys because she could fall from her horse or cause her horse to fall which could result in other jockeys being part of the accident and being harmed.

She also argued that even if a test on a jockey was taken before the race and it tested positive, that jockey would still have ridden in that race. ${ }^{51}$ However, I cannot agree with her argument because as a professional jockey she would be expected not to take drugs and so drug tests before a race are a deterrent to prevent a jockey from taking drugs, as they know that they will be tested and should they ride when under the influence of drugs, they could cause harm to themselves and the other jockeys ${ }^{52}$ and could also face sanctions resulting in their not being allowed to take part in other competitions. By taking drugs, Cropp is harming the NZTR as the public will view the sporting body in a negative light which also causes harm to the integrity of the sport.

By requiring jockeys to take a drug test protects the interests of the jockeys and the NZTR. The drug tests are effective in identifying those jockeys who are taking drugs as well as to deter others. The intrusion is proportional to the limitation of the right to privacy.

If we are to consider a section 5 enquiry, by requiring Cropp to provide a urine sample, her right to privacy might be infringed, but such infringement is justified as it protects the public interest, the interests of the sporting body as well as protecting her safety and that of the other jockeys.

Although her right to privacy is guaranteed in section 21 of the BORA, in the particular case of requiring a urine sample for drug-testing, her right may be justifiably limited. The intrusion of her right to privacy is important given that it is in the public interest that jockeys are tested so as to protect themselves, other jockeys, the sport and the NZTR.

The requirement of a urine sample is prescribed by the Racing Act and the Rules of the NZTR. Section 29 of the Racing Act also makes provision for Rule 528 in order to control the safety of the jockeys. The limitation on Cropp's right to privacy is also reasonable as it seeks to protect her and the other jockeys by finding those jockeys who are taking drugs and preventing them from racing as well as deterring others. As a result, the safety of all the racers is protected.

The limitation of her right is therefore proportional to protecting the interests of others. Cropp's right to privacy was also not completely infringed and limited by having to provide a urine sample. Her right to privacy is only

\footnotetext{
Cropp v A Judicial Committee (High Court) supra [75] and [76]

Cropp v A Judicial Committee (High Court) supra [71].

Cropp v A Judicial Committee (High Court) supra [79] and [81].
} 
limited in so far as she is required to, as a professional jockey, provide a urine sample for drug-testing. Cropp had consented to the drug-testing by submitting to the Rules of the NZTR and so, although there is an infringement of her section 21 right, such infringement is justified.

Therefore, I agree with the judgments of the various courts that whilst there might have been an infringement of Cropp's right to privacy as found in section 21, such infringement is reasonable and justified. Even if it is found that there has been an infringement on an athlete's right to privacy, it doesn't necessarily mean that such an infringement and a limitation are unreasonable as the reason for the infringement needs to be taken into account. I agree with Andrews $\mathrm{J}$ when she says:

"I conclude that where urine samples are taken for the purposes of drugtesting there is an invasion of a person's reasonable expectation of privacy and bodily integrity (protected by $s 21$ of the [BORA]), and a prima facie breach of the right. This does not mean that the limit on the right is not a reasonable one, however."

The Supreme Court, in looking at the intrusion into the right to privacy in requiring an athlete to provide a urine sample for drug-testing with regard to the issues of consent and safety, had the following to say:

"It is hard to see the supply of a urine sample as an interference with bodily integrity, although it can be accepted that a requirement for a sample involves intrusion on personal privacy. But even so, and taking into account that aspect of personal integrity, we are satisfied that the power to make rules for safety requirements in the conduct and control of race meetings authorises the creation of a drug-testing regime intended to deter drug-taking."

After examining Angela Schneider's types of harm as well as looking at the reasoning of the Supreme Court with regards to a limitation being justified as Cropp had consented to the drug-testing, as she had submitted to the rules of NZTR, I agree with the court that the intrusion in this respect is justified as such an intrusion prevents harm to the athlete, other athletes, society and the sporting community.

Although the courts, and in particular the Court of Appeal, focussed on consent and safety instead of focussing solely on a section 5 analysis, it is clear that in their discussion of consent and safety, they had in fact considered a section- 5 enquiry. The courts, in focussing on consent and safety, can also be said to show why the limitation and infringement of Cropp's right was justified. I also agree with the courts that the wording of the Racing Act cannot be said to be contrary to section 21 as Parliament would not have intended this and therefore, the drug-testing was prescribed by law and Cropp had consented to the drug-testing.

The courts were therefore correct in finding that the drug-testing was prescribed by law and, although there was a limitation of Cropp's right in section 21 , such limitation of her right was reasonable and "demonstrably justified in a free and democratic society."

53 Cropp v A Judicial Committee (High Court) supra [53].

54 Lisa Cropp v Judicial Committee (Supreme Court) supra [32].

55 Cropp v A Judicial Committee (High Court) supra [43]. 


\section{WHAT THE CROPP CASE MEANS FOR SOUTH AFRICA}

In terms of section 14 of the South African Constitution:

"Everyone has the right to privacy, which includes the right not to have -

(a) their person or home searched;

(b) their property searched;

(c) their possessions seized; or

(d) the privacy of their communications infringed."

This provision deals, in greater detail than the New Zealand provision, with what constitutes privacy. In addition, section 36 in the South African Constitution also describes in great detail in what circumstances a right may be limited. Section 36 states:

"(1) The rights in the Bill of Rights may be limited only in terms of law of general application to the extent that the limitation is reasonable and justifiable in an open and democratic society based on human dignity, equality and freedom, taking into account all relevant factors, including -

(a) the nature of the right;

(b) the importance of the purpose of the limitation;

(c) the nature and extent of the limitation;

(d) the relation between the limitation and its purpose; and

(e) less restrictive means to achieve the purpose.

(2) Except as provided in subsection (1) or in any other provision of the Constitution, no law may limit any right entrenched in the Bill of Rights."

In terms of this section, the right to privacy can only be limited if the limitation can be said to reasonable and justifiable. In order for such a limitation to be reasonable, the courts would need to look at the nature of the right, the importance of the purpose of the limitation, the nature and extent of the limitation, the relation between the limitation and its purpose, and less restrictive means to achieve the purpose.

Should a case arise in South Africa in which a court is requested to examine the right to privacy of an athlete to submit to a drug test, we might find the courts following a similar line of reasoning as the courts in the Cropp case. The relevant sections in the South African Constitution are similar to those sections found in the BORA. If we are to apply section 14 and section 36 to the case of an athlete who is required to take a drug test, we would be able to determine if their privacy had been limited and, if so, whether such a limitation is reasonable and justified.

The taking of a urine or blood sample can be viewed as a search of the person/athlete. A court would therefore need to look at whether there has been a violation of the right to privacy and whether a limitation on the right can be said to reasonable and justified by looking at the factors set out in section 36 .

In terms of the first factor, the nature of the right to privacy is to protect a person from having his/her person or home searched, his/her property searched, his/her possessions seized, or the privacy of his/her communications infringed. 
The second factor considers the importance of the purpose of the limitation. In the context of sport, the importance and the purpose of the limitation can be said to be to allow for safety in sport, to deter athletes from taking banned substances, and to prevent any stigma that may be attached to the sport through the use of drugs.

The third factor addresses the nature and extent of the limitation. In terms of this factor, the right to privacy of an athlete is only limited in so far as the athlete is required, as member of the particular sport or sport's body, to provide a urine sample to be tested if and when required. It can be argued that there is no absolute violation of the athlete's right to privacy as an athlete's privacy is only infringed in so far as it is necessary to conduct the drug test.

The fourth factor looks at the relationship between the limitation and its purpose, whilst the fifth factor deals with less restrictive means to achieve the purpose. With regard to these factors, the relationship between the limitation and its purpose is that the right to privacy needs to be limited so that the drug-testing can be performed in order to allow for athlete safety, deter doping, and to prevent any stigma. A drug test is the only way that many drugs can be tested for, and so it can be argued that a less restrictive means in limiting the right to privacy does not exist, unless it can be shown that allowing an athlete to submit to a drug test at his/her leisure will help in deterring the use of drugs in sport.

The final part of the enquiry examines the proportionality of the intrusion. Proportionality refers to the balancing of different interests and the weighing up of competing values. ${ }^{56}$ It is necessary to weigh up "the harm done by a law - the infringement of a fundamental right - against the benefits that the law seeks to achieve - the reasons for the law, or the purpose of the law."

If the same reasoning, as was done with regard to the test in section 5 of the BORA, is applied and the different interests are weighed up, it could be argued that the public interest could supersede the athlete's right to privacy. It is necessary to weigh up the right to privacy of the athlete and the rights of other athletes and the public. In doing this, it is necessary to consider public safety and the possibility of harm to other athletes. By providing the sample, the interests of the public and other athletes are being protected because the use of a drug test will be seen as a deterrent as an athlete who tests positive will be sanctioned and will not be allowed to compete in other competitions which in turn minimizes the possibility of harm that could be caused to himself or herself as well as other athletes.

In addition, the use of the drug test will also help in upholding the integrity of the sport and the sporting community.

In weighing up the interests and values of the public and other athletes on one hand and the interests and values of the athlete being tested on the other hand, it is clear that in order to protect the public, other athletes and the athlete from harm as well as to prevent any negative stigma being attached to the sport, such limitation of the right is necessary. And as was

\footnotetext{
S v Makwanyane and Another supra [104].

57 Currie and De Waal The Bill of Rights Handbook 5ed (2005) 178.
} 
stated before, an athlete's right to privacy is not completely limited. It is only limited in so far as the athlete will be required to provide a urine sample to be tested for drugs.

Therefore, in examining these factors, a court may, like the court in the Cropp case, conclude that there is a reasonable and justified limitation for limiting the athlete's right to privacy. In addition, a court may also use the need for safety and the prevention of harm as reasons for limiting the athlete's right. By using the drug test, the sport's organization will be able to protect the athlete from injury as well as deterring the athlete from taking drugs. The drug test also helps in preventing injury to other athletes. Furthermore, the drug test would prevent any negative publicity for the sport or the athlete. A South African court would, therefore, need to weigh up the limitation of the right to privacy against what such a limitation seeks to achieve.

Like in New Zealand, an athlete, in becoming part of that sport's organization, consents to the rules and regulations of the sport's organization and is aware of the possibility that he/she will be tested. They are aware of the fact that they may be required to provide a urine or blood sample at some stage during their sporting career and are therefore aware of the fact that there will be consequences should that sample test positive. It would also seem that an athlete is unlikely to challenge the infringement of his/her privacy should his/her sample test negative for drugs.

Drug-testing in sport is also prescribed by law by means of the creation of the SAIDS Act. This Act deals with drug-testing in sport. It is necessary for this Act to be in line with the South African Constitution. As mentioned above, the mission of the SAIDS is to "detect, deter and prevent the use of prohibited substances and methods in the South African and the international sporting environment, which are contrary to the principles of fair play and the health and well being of athletes." Therefore, as discussed above, the testing for doping in sport can be said to be a reasonable and justified limitation of the right to privacy as the limitation serves the purpose of protecting the athlete and the sport as well as acting as a deterrent. And, as in the Cropp case, it could be argued that this warrants a justified and reasonable limitation on the right to privacy.

\section{CONCLUSION}

In conclusion, whilst an athlete, like any person in society, has the right to privacy guaranteed in section 21 of the BORA and section 14 of the South African Constitution, when drug-testing is involved, that right to privacy may be limited and such limitation may be reasonable. An athlete submits to the rules of the sport's organization which he/she is part of and if drug-testing forms part of those rules, then he/she is required to follow the rules. Drugtesting in sport is necessary not only to find those athletes who are taking drugs and deterring others, but it is also necessary in order to uphold the integrity of the sport as well as protect the safety of all athletes involved.

Therefore, as was seen in the various judgments of the courts in the Cropp case, there will be times when an athlete's right to privacy may be infringed and limited and such infringement and limitation will be reasonable 
and justified as it serves to protect the interests of the sport. Conversely, in South Africa, given the section-36 limitation, such an infringement on the right to privacy may be justified given the purposes of the drug tests and the fact that there are no less restrictive measures that could be used.

Consequently, in sport, when an issue arises over the right to privacy of an athlete to be subjected to a drug test, it would seem that by using a limitation analysis as well as looking at the issues of consent and safety, that right, given the circumstances, could be reasonably limited and such limitation justified.

In a South African context, should such a case come before the courts, the courts may use section 36 of the Constitution as well as the issues of safety and consent in order to determine if the limitation of the right to privacy is justified and reasonable.

As a result, whilst "[a]thletes possess a right to have the privacy of their bodies and belongings or effects respected", ${ }^{58}$ their right to privacy is and will continue to be limited in so far as they are required to submit to a drug test in order to protect everyone involved in the sport and such limitation will be "reasonable and justifiable in an open and democratic society." Therefore, should such a case arise in the context of a constitutional challenge to drug-testing in sport, the courts must consider the necessity for such tests in formulating whether the right to privacy can be justifiably and reasonably limited by implementing section 36 of the Constitution.

8 Singh 2006 http://www.docstoc.com/docs/19767069/SPORT-AND-HUMAN-RIGHTS\# (accessed 2012-09-10). 